\title{
Produção de materiais reciclados como agente de transformação educacional e socioeconômica na região da Zona Oeste do Rio de Janeiro
}

\section{Productions of recycled materials as educational and social-economic transformation agent on Rio de Janeiro South West region}

\author{
1 Alex da Silva Sirqueira assirqueira@gmail.com \\ 2 Alaide de Sá Barreto \\ 3 Patrícia Reis Pinto \\ 4 David Lucas de Carvalho \\ 5 Vanessa Coelho da Silva
}

\footnotetext{
Doutor em Ciência e Tecnologia de Polímeros. Centro Universitário Estadual da Zona Oeste - UEZO.

Doutora em Química. Centro Universitário Estadual da Zona Oeste - UEZO.

Doutora em Tecnologia de Polímeros. Centro Universitário Estadual da Zona Oeste - UEZO.

4 Aluno do ensino médio. Colegio Estadual Carlos Magno Nazareth de Cerqueira.

5 Aluna ensino médio. Colegio Estadual Carlos Magno Nazareth de Cerqueira.
}

\section{RESUMO}

A humanidade produz lixo em demasia e, infelizmente, não descarta corretamente os resíduos sólidos. É comum a presença de grandes quantidades de resíduos plásticos e fibras vegetais em aterros sanitários. Neste trabalho, foram produzidos compósitos com copos descartáveis de polipropileno e fibras de cocos. As composições estudadas foram feitas com $40 \%$ de fibra de coco e $60 \%$ de material plástico descartado. 0 módulo de elasticidade do compósito foi superior ao plástico virgem. $O$ estudo da decomposição do compósito foi realizado por meio da simulação da degradação em solo. As micrografias confirmaram a presença do fungo Aspergillus flavus na superfície do material, sendo o responsável pelo inicio da degradação. 0 impacto social do compósito foi analisado em parceria com escolas e com a Rede de Artesãos. Os compósitos aumentaram a renda familiar dos artesãos e estimularam os alunos da rede pública para o ensino de ciência.

\section{Palavras-chave:}

Reciclagem. Polímeros. Fibra de coco. Ensino médio.

\begin{abstract}
Humanity produces too much waste and, unfortunately, does not make the correct use of waste treatment. The presence oflargeamounts of plastic wasteand vegetable fibers in landfills is common. In this work, composites were produced with disposable polypropylene cups and coconut fibers. The compositions were made with $40 \%$ coconut fiber and $60 \%$ discarded plastic. The elastic modulus of the composite was high than the virgin plastic. The degradation study of the composite was carried out by simulating the degradation in soil, the micrographs confirmed the presence of Aspergillus flavus on the material surface, as responsible for the beginning of the degradation. The composite social impact was analyzed thorough a partnership with schools and artisans. The composites increased the artisans family income and stimulated the public school students to science learning.
\end{abstract}

\section{Keyword:}

Recycling. Polymers. Coconut fiber. High school.

\section{Como você deve citar?}

SIRQUEIRA, Alex da Silva et al. Produção de materiais reciclados como agente de transformação educacional e socioeconômica na região da Zona Oeste do Rio de Janeiro. Cadernos UniFOA, Volta Redonda, n. 45, p. 57-67, abril 2021. 
Produção de materiais reciclados como agente de transformação educacional e socioeconômica na região da Zona Oeste do Rio de Janeiro

\section{INTRODUÇÃO}

Os níveis de degradação ambiental são elevadíssimos, gerando grande desequilíbrio ao meio ambiente (MARQUES, 2016). 0 descarte indevido de material plástico na natureza contribui significativamente para a saturação do planeta, sendo uma das principais preocupações da comunidade científica e da sociedade, considerando que o tempo de vida do plástico é elevado, em torno de 150 anos, tornando o plástico pós-consumo um contaminante de elevada permanência no ambiente. Um material capaz de resistir a mais de 100 anos não deve ser considerado um infortúnio para a sociedade, e sim avaliado como nobre e de alta resistência, permitindo o uso em vários ciclos. É impossível imaginar o mundo contemporâneo sem o uso de material plástico, entretanto é preciso racionalizar a forma de sua utilização e principalmente o seu descarte e reuso (SIRQUEIRA et al., 2009).

Dados do Jornal do Comércio citam que o Brasil produz 11,3 milhões de toneladas de plásticos, sendo apenas 145 mil recicladas (KLEIN, 2019). Com esses dados, torna-se cada vez mais preocupante e urgente à adoção de medidas educacionais e governamentais para o reuso desses materiais (SILVA FILHO; SOLER, 2013).

A separação dos plásticos do lixo orgânico traz uma série de benefícios à sociedade, como, por exemplo, o aumento na vida útil dos aterros sanitários, a economia de energia e a reciclagem (ZANIN; MANCINI, 2015). Além dos plásticos, outros materiais sólidos, às vezes biodegradáveis, como a fibra do coco, o caroço do açaí, as folhas de bananeiras, quando descartados indevidamente, contribuem para a saturação dos aterros sanitários (SILVA FILHO; SOLER, 2013).

A utilização de fibra vegetal, em particular a fibra de coco, como reforço em compósitos com plásticos, cresce devido as suas propriedades intrínsecas, como boa resistência mecânica, conforto térmico e baixa densidade (OVANDO-MEDINA et al., 2020; PELITA; HIDAYANI; RAHMAD, 2019; UDHAYASANKAR; KARTHIKEYAN, 2019). Sabe-se que a completa substituição de fibras sintéticas por fibras naturais é impossibilitada, por razões econômicas, contudo as fibras naturais oferecem algumas vantagens sobre as fibras sintéticas.

As fibras naturais são de fontes renováveis, disponíveis em grande quantidade, biodegradáveis, menos abrasivas e podem ser recicladas. Há existência de disponibilidade em grandes quantidades de fibras vegetais com propriedades mecânicas bem definidas e, geralmente, é pré-requisito para o sucesso desses materiais em compósitos poliméricos (PENG et al., 2012).

$\mathrm{Na}$ cidade do Rio de Janeiro, foi constatado o consumo diário médio (inverno/verão) de 420 mil cocos. Se cada coco gera 1,5 kg de lixo, isso corresponderá a 630 toneladas/dia de lixo. Nessa perspectiva, ao invés de queimar a fibra vegetal, pode-se pensar em novas aplicações (FONTES; FERREIRA, 2006).

Na região da zona oeste do Rio Janeiro, a geração de material sólido pós-consumo é elevada, sendo comum a queima de plásticos e fibras naturais. Na tentativa de reaproveitar os resíduos do coco, é comum o uso de suas fibras em misturas com outros materiais e na produção de objetos como vasos de xaxim. Sabe-se que o uso de tecnologias mais sofisticadas de mistura com termoplásticos ainda é restrita à Universidade e a poucas empresas, porém a utilização da mistura de plástico e fibra de coco pode gerar um produto com maior valor agregado (OVANDO-MEDINA et al., 2020).

É preciso difundir o conceito de reciclagem nas escolas em todos os níveis do ensino, para mitigar a quantidade de resíduos descartados indevidamente no meio ambiente. Este trabalho tem como objetivo mostrar a interação da academia com a sociedade, por meio da produção de compósitos biodegradáveis de fibra de coco e resíduos de copos plásticos. As resistências à tração e à degradação dos materiais biodegradáveis foram caracterizadas. Os biocompósitos foram repassados para os 
artesãos para promover a educação ambiental e assim mitigar o impacto provocado no meio ambiente da região da zona oeste do município do Rio de Janeiro.

\section{MATERIAIS E MÉTODOS}

Os materiais utilizados neste trabalho foram: resíduos de cocos provenientes de quiosques da orla do Rio de Janeiro e copos descartáveis de polipropileno (guaraná natural), como demonstrado na Figura 1.

Figura 1 - Resíduos de (a) fibra de coco e (b) copos plásticos.

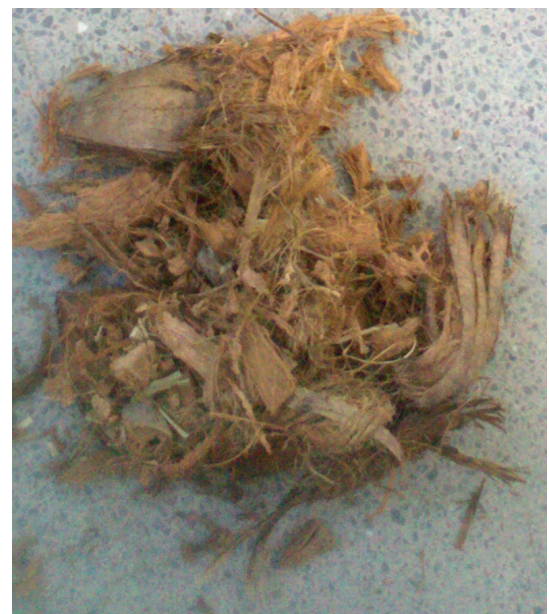

(a)

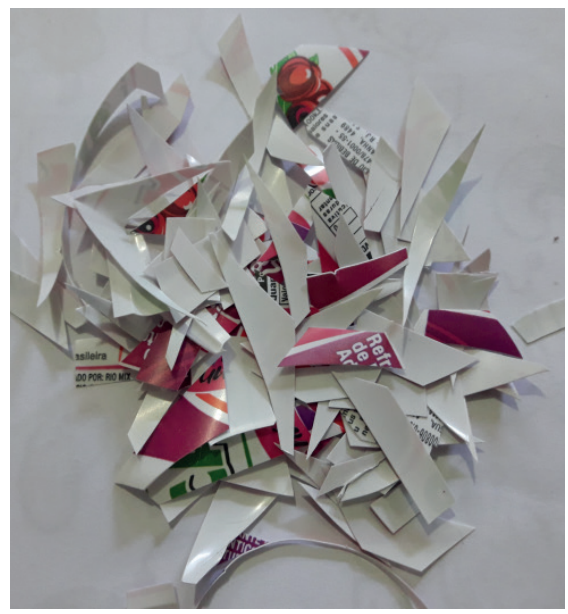

(b)

Fonte: Elaborado pelo autor (2020).

Os materiais foram coletados por alunos do segundo ano do ensino médio, do Colégio Estadual Carlos Magno Nazareth de Cerqueira.

Os cocos foram separados e divididos e, em seguida, foram pesados em balança semianalítica (Shimadzu). Os cocos partidos foram secos em estufa com circulação forçada de ar (Marconi, modelo MA $033 / 5$ ) a $60^{\circ} \mathrm{C}$ por 168 horas. 0 teor de umidade foi determinado pela diferença entre as massas antes e após a secagem, como descrito na Equação 1.

$$
\text { Teor de humidade }=\frac{(\text { Massa após secagem-Massa antes da secagem })}{\text { Massa antes da secagem }} \times 100
$$

Após o processo de secagem, as fibras de coco e os copos plásticos descartados foram moídos em moinhos de facas (SOLAB), apresentado na Figura 2. 
Produção de materiais reciclados como agente de transformação educacional e socioeconômica na região da Zona Oeste do Rio de Janeiro

Figura 2 - Moagem das fibras de coco.

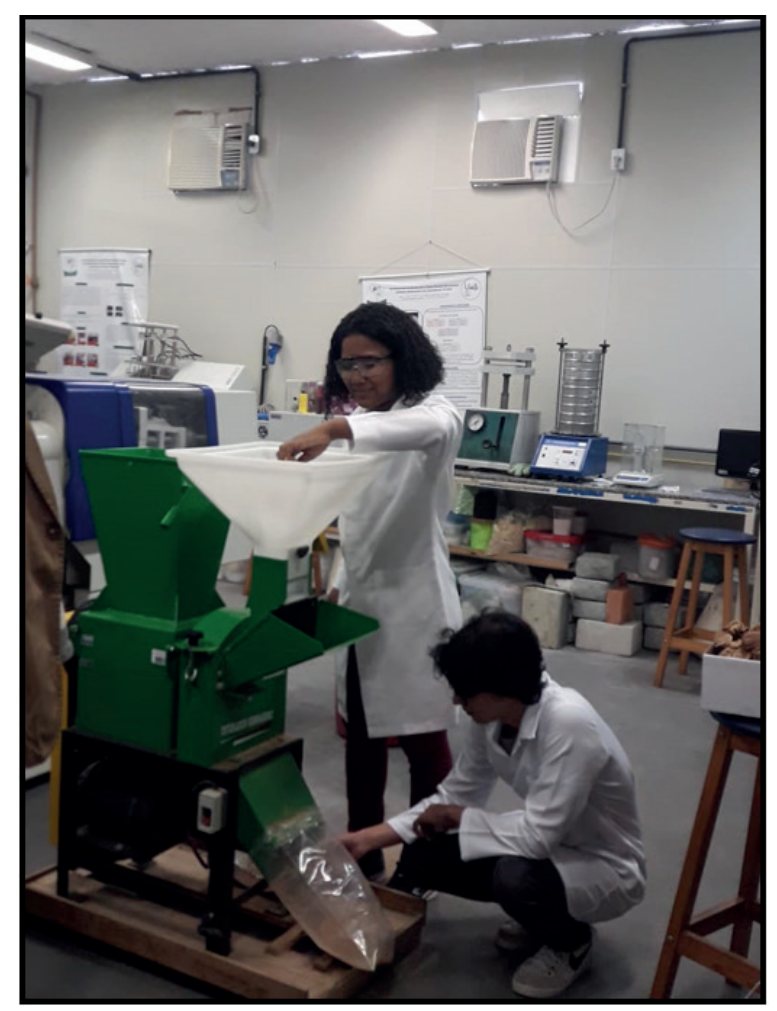

Fonte: Elaborado pelo autor (2020).

As proporções em massa de plástico/fibras estudadas neste trabalho foram 60/40 (p/p).

Os materiais foram processados em extrusora dupla rosca (TECK-TRIL), co-rotante, com velocidade de 45 RPM, tempo de residência de 30 s e perfil de temperatura de 190 a $210^{\circ} \mathrm{C}$, apresentado na Figura 3.

Figura 3 - Extrusora utilizada para o preparo das amostras.

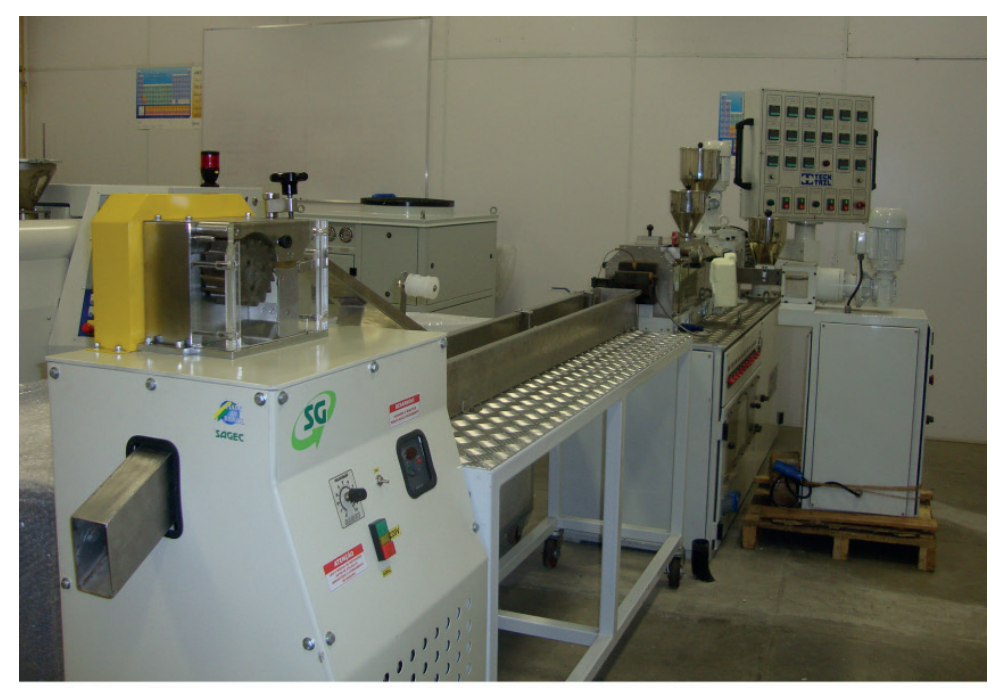

Fonte: Elaborado pelo autor (2020). 
Após o processamento, os materiais foram secos em estufa de circulação forçada de ar (Marconi, modelo MA $033 / 5$ ) a $60^{\circ} \mathrm{C}$ por 24 horas. Em seguida, os materiais foram prensados em prensa hidráulica com aquecimento (Marconi, modelo MA 098/C), à temperatura de $210^{\circ} \mathrm{C}$, sob pressão de 3 toneladas durante 3 minutos.

A propriedade mecânica de resistência à tração foi determinada em máquina universal de ensaios (EMIC, modelo DL 2000), célula de carga de $500 \mathrm{~N}$ e velocidade de separação entre as garras de $100 \mathrm{~mm} / \mathrm{min}$. Os testes foram realizados em 5 corpos-de-prova de acordo com a norma ASTM 882 .

Para investigar o tipo de degradação que ocorrem nos materiais, dois corpos-de-prova de tração de cada amostra foram totalmente enterrados em solo. Após 40 dias, os corpos-de-prova foram desenterrados, lavados e secos em estufa de circulação forçada de ar a $60^{\circ} \mathrm{C}$ por 24 horas. Em seguida, foram obtidas as imagens em microscópio eletrônico de varredura (JEOL, modelo JSM-6701F) e microscópio confocal (SENSOFAR, modelo S Neox). Os fungos foram identificados. Considerando-se a aparência macromorfológica da colônia, análise micromorfológica de ornamentação e o corpo de frutificação, conforme descrito na literatura (ESPÓSITO; AZEVEDO, 2010).

Após a etapa de produção e caracterização do material reciclado, foi realizado contato com grupo de recicladores e artesãos de rede solidária da zona oeste do município do Rio de Janeiro para divulgação do trabalho. Houve grande procura pela capacitação nos cursos de formação. Os cursos de capacitação e as aulas de artesanato foram realizados em salas de aula fora do Centro Universitário Estadual da Zona Oeste (UEZO), sendo que somente as aulas práticas foram realizadas nos laboratórios didáticos da UEZO. Os módulos do curso de extensão universitária estão descritos na Tabela 1.

Tabela 1 - Modulos do curso de capacitação.

\begin{tabular}{lc}
\hline Módulos & Carga horária (h) \\
\hline Apresentação e sensibilização do projeto & 1 \\
\hline Direitos Humanos e Cidadania & 3 \\
\hline Introdução aos plásticos & 6 \\
\hline Meio ambiente, resíduos sólidos e impacto ambiental & 3 \\
\hline Processamento de fibras e plásticos & 15 \\
\hline Economia solidária, autogestão e desenvolvimento & 18 \\
\hline Oficinas artesanais & 24 \\
\hline Avaliação & 2 \\
\hline Exposição dos materiais & 6 \\
\hline Total de horas do curso & 78 \\
\hline
\end{tabular}

Fonte: Elaborado pelo autor (2020)

Ao final dos módulos de capacitação, foi elaborado questionário para avaliação do curso. 0 Quadro 1 apresenta o questionário avaliativo aplicado no final do curso. 
Produção de materiais reciclados como agente de transformação educacional e socioeconômica na região da Zona Oeste do Rio de Janeiro

Quadro 1 - Questionário avaliativo do curso de capacitação.

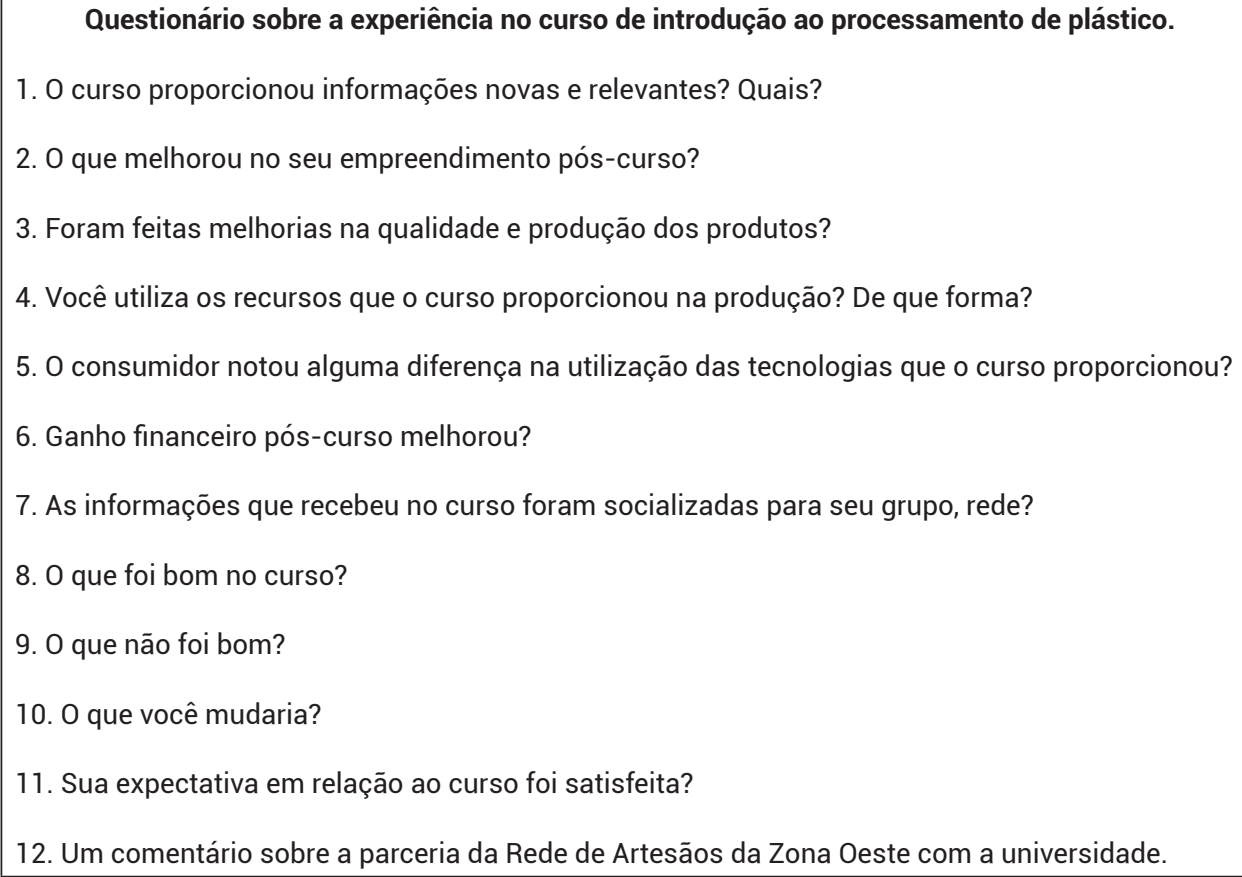

Fonte: Elaborado pelo autor (2020).

\section{RESULTADOS E DISCUSSÃO}

A distribuição granulométrica das fibras e dos resíduos plásticos moídos foi analisada em jogos de peneiras, apresentado na Figura 4. Para este trabalho, optou-se por fibras maiores, até 100 mícrons, pois corresponde a, aproximadamente, $70 \%$ do material obtido nessas condições de moagem.

Figura 4 - Distribuição granulométrica da fibra de coco e do plástico após moagem.

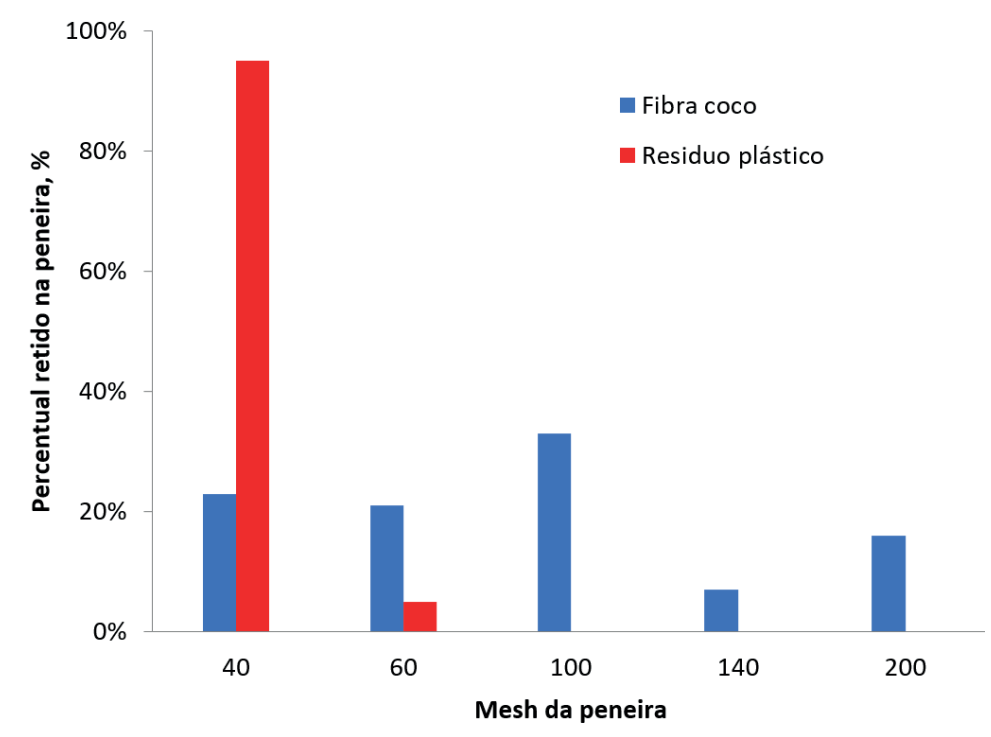

Fonte: Elaborado pelo autor (2020). 
0 teor de umidade médio no coco foi de aproximadamente $80 \%$ do seu peso. Embora a constituição do coco apresente fibras naturais, lignina, celulose e outros, a quantidade de água é superior. A água é responsável por produzir um ambiente favorável à proliferação de fungos e bactérias. Quando descartados de maneira inapropriada, é comum observar colônias na superfície dos cocos.

A Figura 5 apresenta o aspecto final dos materiais produzidos após o processamento e a prensagem.

Figura 5 - Materiais produzidos com os resíduos (a) copo descartável e (b) copo/fibra.

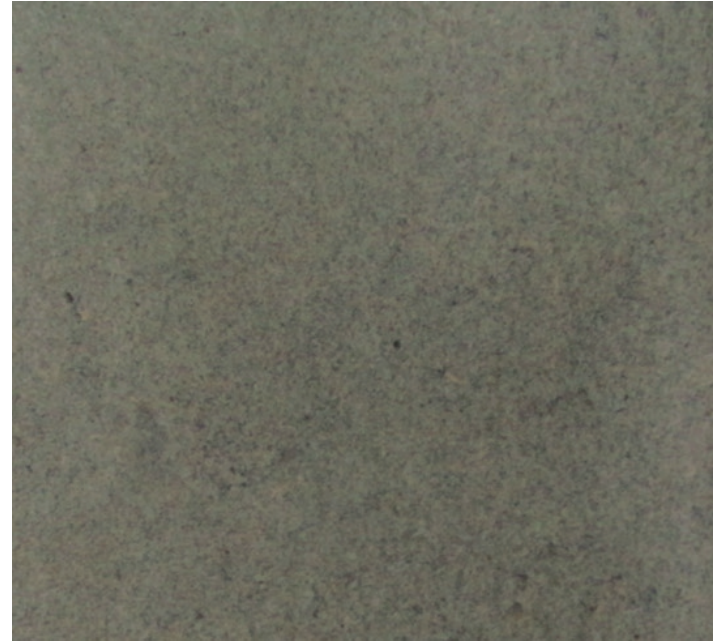

(a)

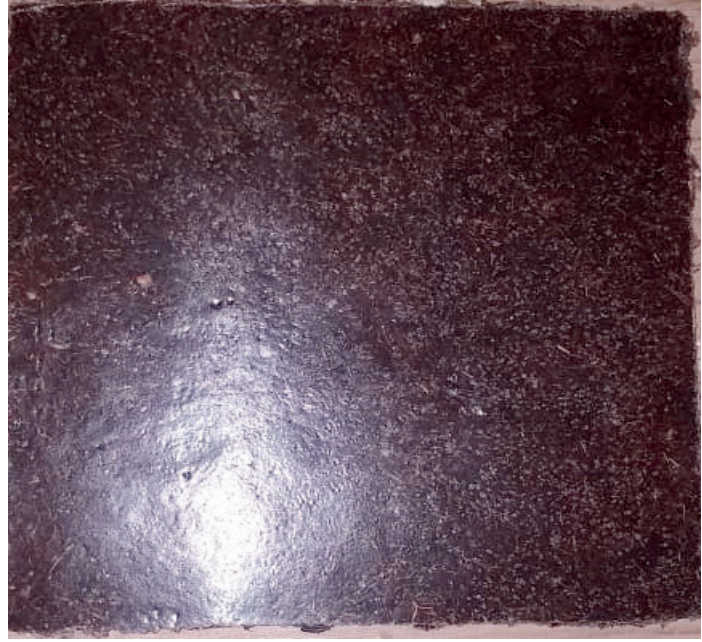

(b)

Fonte: Elaborado pelo autor (2020)

A resistência à tração dos materiais foi avaliada, conforme Tabela 2. 0 compósito apresentou maior módulo de elasticidade em relação ao Polipropileno virgem. O material compósito produzido com resíduos de plástico e fibra de coco pode ser utilizado em aplicações que necessitem de reforço.

Tabela 2 - Propriedade mecânica de resistência à tração.

\begin{tabular}{lccc}
\hline & $\begin{array}{c}\text { Tração de ruptura } \\
(\mathrm{MPa})\end{array}$ & $\begin{array}{c}\text { Módulo de elasticidade } \\
(\mathrm{MPa})\end{array}$ & $\begin{array}{c}\text { Alongamento na } \\
\text { ruptura (\%) }\end{array}$ \\
\hline PP virgem & $33,45 \pm 1,26$ & $69,59 \pm 7,34$ & $758 \pm 25$ \\
\hline PP reciclado & $28,41 \pm 1,83$ & $40,87 \pm 5,74$ & $596 \pm 78$ \\
\hline Compósito (resíduo plástico/fibra de coco) & $25,75 \pm 1,13$ & $75,58 \pm 4,23$ & $450 \pm 11$ \\
\hline
\end{tabular}

Fonte: Elaborado pelo autor (2020)

A análise estatística dos dados de tração na ruptura foi realizada (Excel Microsoft ). Para verificar as influências significativas nas médias de resistência de tração, foi realizado o tratamento estatístico da análise de variância (ANOVA). Os valores do tratamento estatístico para o ensaio de tração são apresentados na Tabela 3. Pode-se afirmar com 95\% de confiança estatística que os valores das médias para tração são diferentes. De acordo com a regra de decisão, se o valor de $p$-calculado $(0,001)$ é menor em relação $\mathrm{p}$-tabelado $(0,05)$, ou, se $\mathrm{F}>\mathrm{F}$ crítico, pode-se afirmar que as médias são diferentes. Assim, os valores médios de tração são diferentes. $O$ fato de se comparar os valores em função do desvio-padrão ou da variância não permite assegurar com precisão estatística se há ou não alteração no valor médio. Se a análise de variância indica que existe diferença significativa entre as médias dos níveis do fator, então o próximo passo da análise consiste em realizar comparações múltiplas para descobrir 
Produção de materiais reciclados como agente de transformação educacional e socioeconômica na região da Zona Oeste do Rio de Janeiro

onde estão localizadas as diferenças detectadas pelo teste F. Existem inúmeros testes estatísticos que localizam as diferenças entre as médias. Dentre eles, tem-se o método de Duncan (MONTGOMERY; RUNGER, 1999). O Método de Duncan é um procedimento muito utilizado para comparações entre todos os pares de médias envolvidos e um estudo de análise de variância, permitindo a manutenção de um nível de significância. Os resultados obtidos indicam que os valores das médias são diferentes para os três materiais estudados.

Tabela 3 - Análise estatística da propriedade mecânica de tração na ruptura.

\begin{tabular}{|c|c|c|c|c|c|}
\hline \multicolumn{6}{|c|}{ ANOVA } \\
\hline Grupos & $\mathrm{N}$ & & Média & $\begin{array}{l}\text { Desvio } \\
\text { Padrão }\end{array}$ & \\
\hline PP Virgem & 6 & & 33,49 & 1,26 & \\
\hline PP reciclado & 6 & & 29,39 & 1,83 & \\
\hline \multirow[t]{2}{*}{ Compósito } & 6 & & 26,78 & 1,13 & \\
\hline & DF & $\begin{array}{l}\text { Soma qua- } \\
\text { drática }\end{array}$ & MS & $\mathrm{F}$ & $P$ \\
\hline Entre grupos & 2 & 137,178 & 68,589 & 33,197 & $<0,001$ \\
\hline Resíduo & 15 & 30,991 & 2,066 & & \\
\hline Total & 17 & 168,17 & & & \\
\hline \multicolumn{6}{|c|}{ Método de DUNCAN } \\
\hline Comparação & $\begin{array}{l}\text { Diferença entre } \\
\text { médias }\end{array}$ & $\mathrm{p}$ & q & $P$ & $P<0,050$ \\
\hline PP virgem vs. Compósito & 6,707 & 3 & 11,429 & $<0,001$ & Sim \\
\hline PP virgem vs. PP reciclado & 4,102 & 2 & 6,99 & $<0,001$ & Sim \\
\hline PP reciclado vs. Compósito & 2,605 & 2 & 4,439 & 0,007 & Sim \\
\hline
\end{tabular}

Fonte: Elaborado pelo autor (2020)

No estudo do ciclo de vida do compósito de plástico reciclado e fibra de coco, foi proposto ensaio de degradação em solo, sendo avaliado por microscopia. A Figura 6 apresenta as microscopias obtidas. Por meio da análise realizada em microscópio confocal, foi possível identificar o tipo de fungo presente na superfície da amostra (Figura 6.a). Os tipos de fungos encontrados na superfície do compósito foram os Aspergillus flavus e niger, porém ocorre predomínio do tipo flavus. O fungo Aspergillus flavus foi identificado como iniciador do processo de degradação do compósito, quando em contato com o solo. Na Figura 6.b (microscopia de varredura), nota-se que as hifas da estrutura do fungo estão sobre a fibra de coco, sendo possível afirmar que a degradação acelerada do material, quando descartado de maneira irregular, ocorrerá com a quebra da fibra de coco. Na superfície da amostra do copo descartado, não foi detectada a presença de colônia de fungos, conforme Figura 6.c. 
Figura 6 - Imagens dos fungos desenvolvidos na superfície do material.

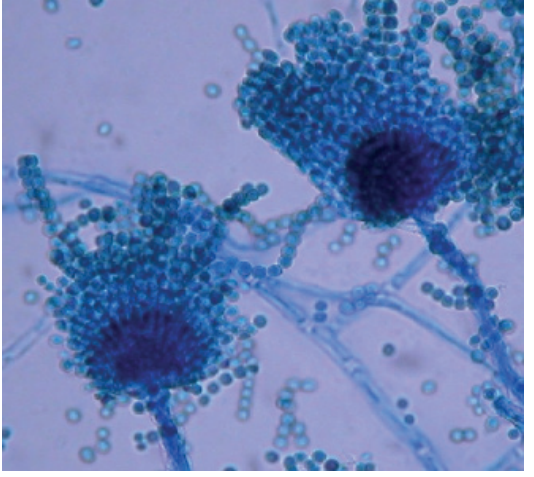

(a)

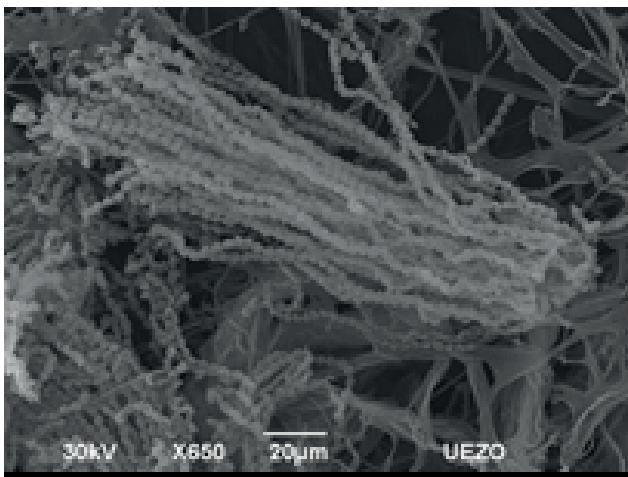

(b)

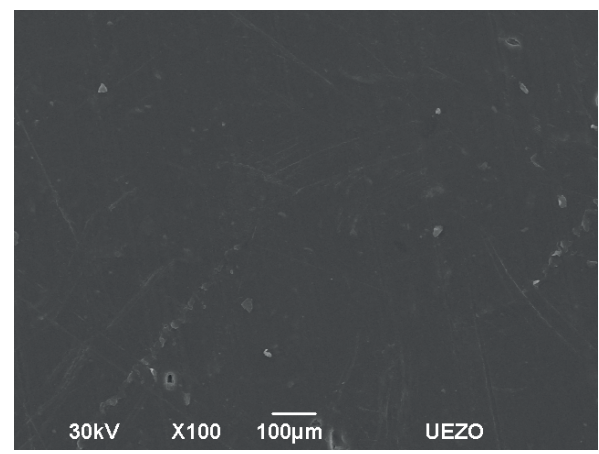

(c)

Fonte: Elaborado pelo autor (2020).

Durante a etapa de sensibilização do projeto para a sociedade do entorno do Centro Universitário, foram convidados grupos de catadores, recicladores, membros de associações de moradores e artesãos. Verificou-se atuação bastante participativa, tanto do grupo de recicladores quanto do grupo de artesãos. No entanto, a despeito da grande participação nas atividades durante o primeiro encontro, apresentando uma aparente motivação dos grupos de catadores e recicladores, não houve interessados nem inscritos no curso básico em processamento de plásticos. A partir desse momento, focou-se no curso para o interesse do grupo de artesões que passou a ser intitulado por "Introdução ao processamento de plásticos para obtenção de material reciclado para ecodesing."

Após a realização de todas as disciplinas do curso de extensão universitária, as respostas do questionário de avaliação foram consolidadas. Todos os participantes entrevistados disseram que o curso foi relevante e as expectativas foram superadas. Também foi mencionada a necessidade de mecanismos de continuidade para a obtenção de mais compósitos com fibra de coco, sendo este o item negativo citado em todas as entrevistas. Quanto à questão sobre a melhoria nos empreendimentos após o curso, responderam que afetou diretamente o artefato produzido. Também foi dito que o curso gerou novas perspectivas "abriu novos horizontes" e uma participante falou ainda do saber adquirido e da possibilidade de transformar o lixo.

Os ganhos financeiros aumentaram para os artefatos artesanais produzidos pela matéria-prima (plástico + fibra de coco) adquirida durante o curso. A motivação delas quanto à possibilidade de estudar mais e saber mais sobre os polímeros foi também relatada nas entrevistas, até mencionaram interesse em saber o custo do maquinário (extrusora e prensa hidráulica) para que pudessem produzir em maior quantidade. A relação do grupo de professores com a Rede de Artesões da Zona Oeste é 
Produção de materiais reciclados como agente de transformação educacional e socioeconômica na região da Zona Oeste do Rio de Janeiro

efetiva até os dias atuais e tem-se buscado um formato que possa atender as demandas colocadas pelos participantes do curso.

Os artefatos artesanais produzidos foram expostos durante a Jornada de Ciência e Tecnologia da UEZO, apresentado na Figura 7. Isso possibilitou maior aproximação dos graduandos com os grupos de artesões locais. Outros graduandos tiveram acesso ao trabalho, se interessaram e se disponibilizaram para trocar saberes.

Figura 7 - Exposição dos artefatos artesanais.

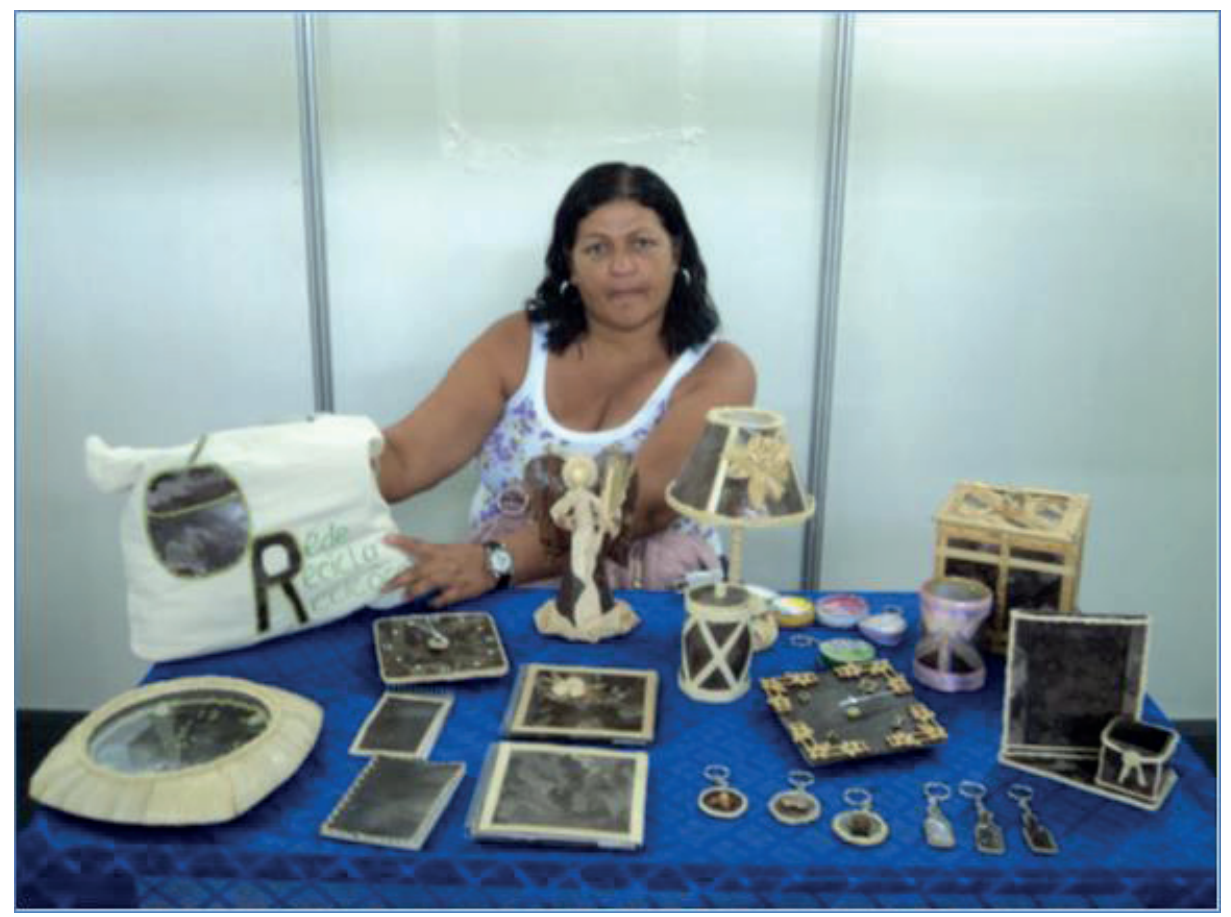

Fonte: Elaborado pelo autor (2020).

\section{CONCLUSÕES}

A redução no teor de material proveniente do petróleo auxilia o meio ambiente na degradação de compósitos com plásticos. O fungo Aspergillus flavus foi identificado como iniciador do processo de degradação do compósito plástico/fibra de coco.

Os artefatos artesanais produzidos pelos compósitos biodegradáveis de copos plásticos fibra de coco apresentaram maior valor financeiro.

A disseminação do conhecimento técnico de reciclagem para os artesão da região de Guaratiba foi alcançada. 


\section{AGRADECIMENTOS}

Os autores agradecem pelo apoio financeiro da Fundação de Amparo à Pesquisa do Estado do Rio de Janeiro (E-026/200.019/2019) e do Programa Jovens Talentos (243351).

\section{REFERÊNCIAS}

ESPÓSITO, E.; AZEVEDO, J. L. Fungos: uma introdução à biologia, bioquímica e biotecnologia. 2. ed. Caxias do Sul: Educs, 2010.

FONTES, H. R.; FERREIRA, J. M. S. A cultura do coco. 1. ed. Brasilia: Embrapa Informação Tecnológica, 2006.

KLEIN, J. Reciclagem é a resposta do setor do plástico para evitar banimento. Jornal do Comércio, 30 set. 2019.

MARQUES, L. Capitalismo e colapso ambiental. 2. ed. rev. ed. Campinas: Editora da UNICAMP, 2016.

MONTGOMERY, D. C.; RUNGER, G. C. Applied Statistics and Probability for Engineers. 2. ed. New York: John Wiley \& Sons, Inc., 1999.

OVANDO-MEDINA, V. M. et al. Interfacial photothermal water evaporator based on nanoporous microwaveexpanded graphite and coconut fiber@recycled polystyrene as substrate. International Journal of Energy Research, v. 2, n. 2, p. 57-75, 2020.

PELITA, E.; HIDAYANI, T. R.; RAHMAD, D. Potency of paper mill waste as recyclable polypropylene filled with coconut fiber composite for mitigational material. Rasayan Journal of Chemistry, v. 12, n. 3, p. 1144-1150, 2019.

PENG, N. et al. Progress in Polymer Science Evolution of polymeric hollow fibers as sustainable technologies: Past, present, and future. Progress in Polymer Science, v. 37, n. 10, p. 1401-1424, 2012.

SILVA FILHO, C. R.; SOLER, F. Gestão de resíduos sólidos. 4. ed. São Paulo: Trevisan Editora, 2013.

SIRQUEIRA, A. S. et al. Nitrigreen a Borracha Ecológica. v. 19, p. 10-13, 2009.

UDHAYASANKAR, R.; KARTHIKEYAN, B. Preparation and properties of cashew nut shell liquid-based composite reinforced by coconut shell particles. Surface Review and Letters, v. 26, n. 4, p. 1-17, 2019.

ZANIN, M.; MANCINI, S. D. Resíduos plásticos e reciclagem: aspectos gerais e tecnologia. 2. ed. São Carlos: EdiUFSCAR, 2015. 